\title{
UM CASO DE BINSWANGER SOB A LENTE DE MERLEAU-PONTY
}

\author{
Ronaldo Manzi Filho
}

Resumo: Pretendo, neste artigo, abordar um caso de Binswanger privilegiado por Merleau-Ponty. Nesse caso, o filósofo desenvolve a questão do estatuto do sintoma como uma forma de elaboração de vida, mas chega num impasse: como pensar essa elaboração sem que isso nos leve a negar que o sujeito se reestrutura totalmente diante de um impasse? Além do que, o que significa dizer que o sujeito elabora uma nova forma de vida? Veremos como a análise merleau-pontyana da psicanálise é peculiar, levando-o a negar um conceito chave da metapsicologia freudiana: o inconsciente.

Palavras-chave: Sintoma. Decisão. Inconsciente. Drama. Sentido.

Em 1951, Merleau-Ponty escreve um texto (L'homme et l'adversité) sobre os avanços da filosofia nos primeiros 50 anos do século XX. O curioso é que ele descreve esse avanço com ausência de referência a qualquer filósofo e mesmo a algum fenomenólogo senão alusivamente. Isso demonstra de modo peculiar como seria possível dizer como a filosofia se configurou no século $X X$ em relação às não filosofias. Ora, é notável como uma história da filosofia pode ser reescrita sem referência a um filósofo.

Na verdade, Merleau-Ponty se debruçou em várias áreas do saber científico para questionar aquilo que a filosofia, ao menos francesa (na década de 50), excluía de seu domínio, mas que poderia nos levar a pensar de outra forma. Como se Merleau-Ponty tivesse algo muito sutil, mas fundamental, a advertir a seu tempo: 
"estrabismo da fenomenologia: a atitude natural, a não filosofia, é o segredo dos segredos" (Merleau-Ponty, 1957, p. 117). Um exemplo disso é sua interpretação da psicanálise freudiana. Parece-me que aí o filósofo consegue convergir de modo astuto sua experiência filosófica com as reflexões psicanalíticas.

Nesse artigo, pretendo mostrar como essa interpretação da psicanálise é fundamental para que o fenomenólogo articulasse o problema da temporalidade do sujeito com o sentido do sintoma em suas primeiras elaborações teóricas. Na verdade, essa articulação o leva a uma questão interessante:é preciso que se negue a noção de inconsciente proposta por Freud e privilegiar a operação gestaltista de figura/fundo na própria consciência. Para podermos acompanhar esse raciocínio, podemos retomar um caso privilegiado por Merleau-Ponty que ele toma de Ludwig Binswanger, caso que compreendemos se partimos do estatuto do sintoma para o filósofo.

\section{O estatuto do sintoma - um caso de Binswanger}

O sintoma na Phénoménologie de la Perception aparece como uma atitude do sujeito, como o exemplo de como este resolve seus conflitos levando em conta a história da sua vida. Em La Structure du Comportement, Merleau-Ponty (2002a) afirmou que "o sintoma é uma resposta do organismo a uma questão do meio" (p.67), mas uma resposta que impunha uma reestruturação do organismo e uma atitude normativa ao meio. Na Phénoménologie de la Perception o sintoma é, de certo modo, também uma resposta, mas diante de um impasse existencial que o sujeito coloca para si diante da sua história e de outrem. A história sexual seria assim uma elaboração de uma forma geral de vida, sendo o sintoma parte dessa elaboração, pois

\footnotetext{
se a história sexual de um homem oferece a chave de sua vida, é porque, na sexualidade do homem se projeta seu modo de ser em respeito ao mundo, quer dizer, em respeito ao tempo e em respeito aos outros homens. (MerleauPonty, 1967, p. 185)
}

De fato, para Merleau-Ponty, o sintoma não é algo patológico em si, mas um modo de elaborar a forma de vida diante de um impasse. Aliás, uma interpretação claramente politzeriana, quando este afirma, por exemplo, que o fato psicológico (tal como o sonho) é um segmento da vida individual particular.

$\mathrm{Na}$ verdade, o sintoma ganha um estatuto fundamental, porque ele pode, nas mãos de um psicanalista, revelar as dimensões fundamentais da existência, uma vez que se fia à história do sujeito e à sua relação com outrem. $\mathrm{O}$ sintoma não pode assim ser visto como um signo que repre- 
senta uma significação: ele não representa algo, ou manifesta algo, nem mesmo um estado interior. Ele é o que significa: a própria expressão da elaboração de uma forma de vida. Como disse, Merleau-Ponty traz um exemplo de Binswanger para especificar essa problemática.

Trata-se de uma jovem que foi proibida, pela mãe, de rever um rapaz que ela amava. Por essa interdição, a jovem perde o sono, o apetite e, por fim, o uso da fala. Binswanger destaca como a jovem já tinha tido sintomas semelhantes na infância. O que é interessante para MerleauPonty é o fato de podermos interpretar esse caso não de um modo "estritamente freudiano", como ele frisa, mas existencial: em vez de destacarmos uma fixação numa fase do desenvolvimento infantil (a oral) poderíamos pensar que a recusa da fala seria uma recusa de coexistência - recusa de falar, de comer, de se veicular com o mundo e com outrem pela boca. Assim, o filósofo coloca em primeiro plano a linguagem (material concreto da narrativa que nos aponta Politzer) e não uma fase do desenvolvimento.

Há de se destacar como Merleau-Ponty diz de uma escolha (decisão) e não de uma recusa deliberada. Isto é, não se trata de deliberar uma alternativa diante de variáveis possíveis. Ao contrário, o sujeito, diante de uma situação de interdição, só consegue resolver esse impasse existencial por uma forma de recusa muito específica: a jovem escolhe não se relacionar com ninguém ao se deparar com o barramento da sua libido. Uma recusa de coexistência: um meio de "fugir da situação", já que enfrentá-la seria, para ela, mais angustiante que esse isolamento. Por isso se trata de uma escolha: ela não teria como deliberar outra forma de solução porque não faz parte de sua história libidinal.

Merleau-Ponty segue aqui claramente uma inspiração politzerina: só podemos compreender a escolha de um sujeito diante de sua história pessoal, ou seja, diante de sua narrativa. Basta lembrarmos que essa recusa existencial da jovem em coexistir com outrem parece repetir uma recusa que ela já tinha feito quando criança pela escolha do mesmo sintoma diante da morte de alguém próximo - ela reabre o tempo a partir das implicações do presente, pois "nós podemos sempre encontrar em nosso passado o anúncio daquilo que nos tornamos" (Merleau-Ponty, 2004, p. 28). Isso nos mostra como só podemos compreender o sentido do ato da jovem seguindo a narrativa do próprio sujeito como elogiava Politzer ao analisar a psicanálise.

A psicanálise teria assim o mérito de resgatar a narrativa pessoal como método de análise e de acesso à subjetividade, porque ela jamais abandona o indivíduo concreto. Nesse caso, a história particular de cada um é fundamental, e é nesse sentido que Merleau-Ponty (1967) resgata Politzer, para justificar sua definição de libido:"ela [a libido] é o que faz com que o homem tenha uma história" (p. 185). Ou seja, não temos como dissociar a história sexual de um homem da história de sua vida, e não 
temos como explicar uma pela outra, porque uma está tão arraigada à outra que somente poderíamos afirmar que um sujeito teve esta história de vida porque ele teve esta história sexual, porque esse é o drama de sua vida. Assim, só podemos compreender o sintoma do caso da jovem que descrevíamos acima a partir de sua história pessoal.

Outro modo de pensarmos isso é retomando uma análise que Merleau-Ponty realiza de Cézanne num famoso artigo intitulado Le doute de Cézanne (escrito na mesma época que a Phénoménologie de la Perception). O filósofo começa o texto questionando por que Cézanne, pouco antes de morrer, colocou em dúvida sua vocação pela pintura. Descreve, ao mesmo tempo, o caráter esquizoide do pintor e pergunta se a perda da flexibilidade do pintor em relação aos outros homens, sua incapacidade de dominar novas situações, sua restrição comportamental aos hábitos, enfim, se todos os seus sintomas de caráter esquizoide determinam o sentido da sua obra. A resposta de Merleau-Ponty segue a mesma lógica que a descrição da história sexual: se só podemos compreender a história de vida de um sujeito porque ele teve essa história sexual (pois esse é o drama de sua vida), do mesmo modo só podemos compreender a obra de Cézanne porque ele teve esse modo de vida.

Se, por outro lado, temos a impressão de podermos explicar sua obra a partir da sua vida é porque conhecemos sua obra e que, a partir dela, buscamos compreender as circunstâncias da sua vida e vice-versa. $\mathrm{O}$ que Merleau-Ponty quer mostrar pode ser compreendido, em termos heideggerianos, como uma coesão de vida: a obra de Cézanne e sua vida participam de uma mesma aventura, de um mesmo drama ou de um mesmo modo de elaborar sua forma de vida. Ou seja, o modo como o sujeito elabora seus sintomas não pode ser dissociado do modo como ele dá sentido à sua obra.

Entretanto, como é possível essa coesão de vida e dizer ao mesmo tempo de uma reestruturação do organismo? Ou seja, se o sujeito reestrutura sua conduta ao longo da vida, ele não modificaria seu modo de ser ulterior? Talvez o melhor modo de compreendermos isso seja nos voltando aos cursos que Merleau-Ponty lecionou em Sorbonne focandonos, principalmente, no tema do desenvolvimento infantil.

\section{O desenvolvimento infantil}

O tema sobre o desenvolvimento infantil aparece em vários momentos nos cursos do filósofo em Sorbonne. Entretanto, a própria noção de desenvolvimento infantil é ambígua: "noção paradoxal, pois ela não supõe nem continuidade absoluta, nem descontinuidade absoluta, quer dizer que o desenvolvimento não é nem adição de elementos homogêneos, nem uma série de etapas sem transição" (Merleau-Ponty, 1988, p. 
245). Isso é fundamental, senão negar-se-ia uma das teses mais importantes da Phénoménologie de la Perception: a temporalidade do sujeito. Ou seja, se a criança, em cada etapa do desenvolvimento, superasse definitivamente a etapa anterior, estaríamos como que afirmando que o sujeito não contaria mais com esse passado, ou que só tivesse contado com ele para se reestruturar e não estivesse mais em operação, de algum modo, no presente.

Por exemplo, no caso da jovem descrita por Binswanger, ela retoma certa conduta passada. Mas é claro que, frente a uma nova situação, essa conduta tem um novo sentido, entretanto, de algum modo, ela conta com seu passado na sua relação com o presente. Modo de dizer que só podemos compreender a conduta do sujeito frente a seu drama - aquilo que ele conta na situação presente. Ou ainda, que as escolhas do indivíduo são coerentes com seu passado.

Mas aqui podemos cair em outro problema: como explicar então a reestruturação do organismo? Ou mesmo, no caso da afasia, em que o sujeito reestrutura seu modo de ser frente ao meio, ele não estaria de algum modo superando uma estrutura anterior? Aliás, como é possível explicar as antecipações no desenvolvimento infantil e regressões no adulto?

Tal questão é sugerida por Freud, mas nos traz um problema difícil para pensarmos o desenvolvimento da estrutura psíquica infantil. Isso porque, se é possível pensarmos a passagem de uma fase a outra enquanto uma reestruturação do psíquico, como indica claramente MerleauPonty em vários momentos, tem-se assim que explicar como traços ou modos de relação de uma fase anterior continuam valendo para o indivíduo, mesmo em idade adulta. Ou seja, como é possível dizer de uma organização genital fálica acrescentando, ao mesmo tempo, traços perversos característicos de uma fase denominada por Freud de "sádico-anal"?

Merleau-Ponty (1988) não deixa de reparar essa suposta contradição:

todas as fases trazem suas contribuições à vida adulta: os componentes orais dão uma energia voltadas ao futuro; os componentes anais fornecem outras suportes na perseverança: algo de profundo e contínuo. Mesmo o sadismo fornece um suporte positivo dando o espírito de luta. Só há, de fato, uma ultrapassagem relativa. Os psicanalistas estão longe de pensar que a passagem está como anulada. O caráter normal tem componentes pré-genitais. Cada fase recolhe e elabora os suportes das fases precedentes. No momento em que ele foi amamentado, permanecem traços no homem. (p. 350)

Como pensarmos essa articulação? Para o filósofo, é a partir da noção de forma que se deveria pensar as fases do desenvolvimento infantil. Por quê? 
Podemos pensar isso recorrendo ao que Merleau-Ponty descreve sobre a consciência infantil: mesmo nos primeiros dias de vida, não podemos pensar a consciência da criança como um caos, mas a partir de certa ordem, mesmo que muito simples, pois"tudo confirma que a experiência infantil não começa pelo caos, mas já num mundo, da qual a estrutura é apenas lacunar" (Merleau-Ponty, 1988, p. 192). Nesse sentido, ao se dizer que há uma estrutura da consciência infantil, se diz que há ordens de organização da consciência. Enfim: não podemos pensar a consciência infantil como se pensa a consciência de um adulto, pois se assim o fizéssemos, pensaríamos o que faltaria para a criança ser um adulto.

Ora, do mesmo modo que, para Merleau-Ponty, seguindo Goldstein, não podemos pensar o doente num sentido negativo (o que falta para ele para ser"normal"), não podemos pensar no que faltaria à criança para ser um adulto. Agiríamos assim como se pressupuséssemos que a criança tivesse uma consciência inacabada, imperfeita. Merleau-Ponty age como se prevenisse os leitores das análises piagetianas que, seguindo o filósofo, buscam mais o que falta à criança (sua não completude) do que saber o que ela realmente é. Ou seja, Piaget parece buscar explicar o adulto recorrendo à criança e a criança recorrendo ao adulto, afirmando assim uma espécie de "continuísmo" ou uma "evolução", como se "daqui para ali" se desenvolvesse progressivamente. Por esse caminho, Piaget parece apontar uma perspectiva do desenvolvimento infantil em função do adulto.

Isso significa que Piaget, segundo Merleau-Ponty, considera a criança como "germe" em direção à maturidade ou como algo imperfeito que tende a se aperfeiçoar - um ser com tendência a um "acabamento" adulto. Se assim fosse, a criança passaria sucessivamente por processos que tenderiam a uma coerência cada vez mais complexa, como se, em cada fase, a percepção do mundo estivesse em vias de se completar cada vez mais nas relações próprias dos esquemas de ação da criança.

A censura merleau-pontyana, percebamos, não é um mero acaso. Por essa via, a criança agiria como se o mundo impusesse a ela certa conduta, apontando mais um sentido negativo da percepção e menos o que Ihe é própria. Haveria assim sempre uma insuficiência perceptiva, já que seria preciso pensar a estrutura cognitiva infantil como algo imperfeito. Se isso fosse verdade, a descrição da percepção seria a descrição de uma história evolutiva de adequação do percebido, e jamais poderíamos acompanhar a noção de ordem no campo perceptivo que a Gestalttheorie nos apresenta. Mas como pensarmos que a estrutura da consciência se reestrutura e se transforma sem com isso dizermos de uma evolução?

Pensando no desenvolvimento infantil, Merleau-Ponty (1988) afirma: "o desenvolvimento não está inscrito a priori numa natureza dada, não surge ex nihilo, ele progride de Gestaltung em Gestaltung, como um escritor cria pouco a pouco sua linguagem" (p. 282). Ora, se for possível 
dizer de uma passagem de Gestaltung em Gestaltung, há de se levar em conta o modo como o passado é integrado numa nova reestruturação, sem com isso excluir uma possível "regressão" do sujeito a estágios anteriores. Como é assim possível dizer de uma reorganização e de uma espécie de passado em reserva?

Merleau-Ponty parece solucionar esse problema em moldes hegelianos, como ele mesmo aponta: é preciso pensar uma noção de Gestalt no sentido hegeliano. Quer seja, é necessário afirmar certa transformação que conserva e, todavia, ultrapassa. Algo como: para se compreender a passagem de uma fase à outra devemos retomar uma ideia análoga à de Hegel sobre a superação: conservar transformando.Vale citarmos toda a passagem em que Merleau-Ponty (1988) aponta isso:

A predominância do arcaico é um fundo sobre a qual devemos construir nosso presente e nosso futuro que apresentarão dificuldades na medida em que o passado não tiver sido integrado:são várias soluções que se oferecem a nós. Não é mais preciso crer que o presente suprime o passado. Devemos retomar uma ideia análoga àquela de Hegel sobre a passagem: conservar transformando. (p.350)

Merleau-Ponty (1988) precisa afirmar assim que "existe um germe que prepara a fase seguinte" (p. 312), do mesmo modo que "não se pode concluir que uma conduta é ou não adquirida em todos os níveis" (p. 287). Ou seja, certo modo de passagem que não seja nem pura transformação, ultrapassagem ou conservação e que torne possível que a "cada vez que o adulto esteja em dificuldade ele tenha a tendência de regressar em direção aos modos de conduta de sua infância, influenciado diretamente por suas relações com seus pais" (p. 329). Modo de dizer que uma reorganização não liquida absolutamente o que lhe precedeu, mas que há uma integração das novas funções na espontaneidade do sujeito: uma integração de um passado que se conserva com certo modo de ultrapassagem. Nesse sentido, poderíamos ainda dizer de uma passagem de Gestaltung em Gestaltung?

Segundo Merleau-Ponty (1988), sim, desde que não pensemos em termos de estruturas rígidas, mas que de certo modo se justaporiam ou se entrecruzariam, ou mesmo, que se invadissem. Nesse sentido, o passado continua valendo para o sujeito e não seria simplesmente superado ou anulado, estando sujeito sempre a uma possível regressão. Essa passagem do filósofo é precisa:

uma vez realizado, o passado deveria ser perfeitamente reabsorvido. Pois, de fato, as formações passadas não são anuladas, as formações novas não são o resultado de uma atividade de pura intelecção, mas de uma Gestaltung vital, concreta, sempre parcial, sempre capaz de regressão, menos estável do que seria um progresso de pura intelecção. (p. 320) 
Com isso em mãos, podemos nos voltar novamente ao caso da jovem descrita por Binswanger: compreendemos assim que seu sintoma ressignifica um traço no passado que permanece valendo para ela num impasse presente. Entretanto, o que significa, tanto no caso da jovem como de Cézanne, o sintoma? O que significa dizer que ele é uma elaboração de uma forma de vida?

\section{Condenado ao sentido}

Dizer que o sintoma é uma elaboração de uma forma de vida, que ele é uma escolha que participa do drama individual, significa afirmar, para Merleau-Ponty, que ele tem um sentido. Aliás, essa é a descoberta freudiana que converge com a fenomenologia a seus olhos: não só o sintoma, mas tudo tem um sentido. Ou, como diz no prefácio:"é preciso compreender todos os lados ao mesmo tempo, tudo tem um sentido, nos encontramos em todas as relações sob a mesma estrutura de ser" (Merleau-Ponty, 1967, p. xiv). Isso por uma razão muito simples: "porque estamos no mundo, estamos condenados ao sentido" (p. xiv). O que isso significa?

Primeiramente, que toda ação, gesto, fala e expressão do sujeito tem um sentido. Merleau-Ponty insiste nisso em vários momentos. Desde a compreensão da criança do sorriso da mãe até a poesia de Paul Valéry:o caminhar de uma pessoa na rua, a expressão de cólera de um amigo, a lembrança que este momento me suscita... Na verdade, ele denomina a elaboração de uma forma geral de vida como um estilo de ser. Mas também uma obra de Cézanne me remete ao estilo desse artista. É nessa noção de estilo, na expressão de um sentido de uma forma de vida num dado momento, que Merleau-Ponty compreende por sintoma: algo que expressa certo estado da sexualidade. A recusa de falar, da jovem descrita por Binswanger, por exemplo, não é um déficit da fala, mas um modo de ser, de se relacionar com o mundo e de se pôr diante da coexistência. O sintoma, nesse caso, expressa uma atitude do sujeito. Ela acusa um sentido que pode ser compreendido, interpretado, mas jamais explicado de modo definitivo.

Parece-me que é por isso que Merleau-Ponty não participa da leitura tradicional da psicanálise dos filósofos de sua época, como de H. Le Savoureux: como se ela apenas nos mostrasse o sentido e a essência da doença e não nos desse a sua causa. Para Merleau-Ponty (1967), há um contrassenso nesse tipo de afirmação: "não se tem a escolha entre uma descrição da doença que nos daria o sentido e uma explicação que nos daria a causa e não há explicação sem compreensão" (p. 134). Por quê?

Merleau-Ponty é astuto ao afirmar que a causa de um fato psíquico não é outra causa psíquica: é preciso compreender o fato, e não remetê- 
lo a outro. Ele quer frisar com isso que ele não partilha de um modo de pensar a psicanálise que parece ter sido dominante na academia francesa nessa época. Um exemplo:

"a relação do signo à coisa significada requer um fundamento", escreve M. Dalbiez... este fundamento é a ideia da causalidade. Se a fumaça é o signo do fogo, é porque ela é o efeito.... Proposição que só vale para os processos normais... Em patologia mental,é preciso desarranjar a ordem dos termos e admitir que a fumaça não é sempre o signo de fogo. (Savoureux, 1939, p. 327)

Por outro lado, poderíamos perguntar: o que é compreender um fato? Aos olhos do fenomenólogo, é interpretá-lo,"pois a explicação não é descoberta, mas inventada, ela jamais é dada com o fato, ela é sempre uma interpretação provável" (Merleau-Ponty, 1967, p. 134). Isso significa afirmar que nenhuma explicação é definitiva ou exclusiva - ela está sempre aberta à nova interpretação ou compreensão (já que seria uma quimera pretender assumir a situação vivida pelo doente).

Com isso, ao afirmar que tudo tem um sentido, ele não afirma que esse sentido seja determinado e sim que estamos diante de uma indeterminação: não há como escolher ou induzir uma interpretação, pois toda interpretação é plausível diferentemente dos fatos físicos que tratam de probabilidades.Sem dúvida, seu objetivo é recusar o pensamento causal, uma vez que o objeto da psicologia, segundo Politzer - o fato psíquico não é de natureza causal. Esse é um dos méritos da psicanálise que Merleau-Ponty reconhece: ela jamais tenta explicar um fato psíquico a partir de relações causais e necessárias, mas por motivações que, a princípio, são possíveis: não há nenhum acontecimento na vida do sujeito que possa determinar um ato futuro, mas somente motivações possíveis.

Assim Merleau-Ponty (2004) não só afirma que tudo tem um sentido como complementa que todo sentido é ambíguo: eles se sobredeterminam. "A verdade é que nossas ações não admitem um único motivo e uma única explicação, e que são, como disse Freud com profundidade, 'sobredeterminados'" (p. 47). Para o filósofo, isso não significa dizer que um sintoma ou um sonho, por exemplo, tenham várias causas. Significa, ao contrário, que um sentido jamais é claro: ele é ambíguo, me remete para algo além dele mesmo que, nos seus termos, define a percepção como um ato violento.

Por outro lado, poder-se-ia concluir que o método psicanalítico como sendo indutivo, pois"o verdadeiro método indutivo não é um 'método de diferenças', ele consiste em ler corretamente os fenômenos, a tomar o sentido, quer dizer, a tratá-los como modalidades e variações do ser total do sujeito" (Merleau-Ponty, 1967, p. 125). De fato, a análise freudiana busca a interpretação de sentidos soterrados na história do sujeito que indique a elaboração da forma de vida que o sujeito se decidiu. Mas 
esse método indutivo, para Merleau-Ponty, não pode ser aplicado a rigor na psicanálise, pois,

se o objeto da psicanálise é de descrever essa mudança entre o futuro e o passado e de mostrar como cada vida sonha sobre os enigmas cujo sentido final não está inscrito antes em lugar nenhum, não se pode exigir dela o rigor indutivo. (Merleau-Ponty, 2004, p. 32)

Um exemplo é a análise freudiana de uma lembrança infantil de Leonardo da Vinci (Eine Kindheitserinnerung des Leonardo da Vinci).

Aos olhos de Merleau-Ponty (2004),"se Freud quer decifrar o enigma antes do que se sabe sobre a significação do voo das aves, sobre o fantasma de fellatio e suas relações com o tempo de amamentação, protestaremos sem dúvida" (p. 29). Quer seja a lembrança de da Vinci verdadeira ou um fantasma que ele constitui na idade adulta, como desconfiava Freud, há sobredeterminações de sentidos que jamais nos garantem uma interpretação unívoca. É certo que Merleau-Ponty acompanha Freud ao tentar compreender o modo de vida de da Vinci em relação à sua história pessoal e não tenta desacreditar a intuição do psicanalista. Mas há algo de arbitrário e insuficiente, a seu ver, em sua explicação:por que isso e não outra coisa? A questão parece impor uma espécie de sobredeterminação.

Em outras palavras, as muitas possibilidades de se tomar um sentido, de interpretá-lo, de relacionar os sentidos sobredeterminados possíveis, faz da interpretação apenas uma sugestão que jamais podemos provar, sem com isso eliminar sua validade:

como imputar ao acaso os complexos convenientes que os psicanalistas descobrem entre a criança e o adulto? Como negar que a psicanálise nos tem instruído a perceber, de um momento a outro da vida, os ecos, as alusões, as retomadas, um encadeamento que não sonharíamos em colocar em dúvida se Freud não tivesse feito corretamente a teoria? (Merleau-Ponty, 2004, p. 31)

É por isso que Merleau-Ponty pode afirmar que a interpretação psicanalítica triunfa, mas com uma reserva: somente sobre o papel, já que não podemos nem negar sua interpretação, nem validá-la por completo - pois não podemos ter acesso às associações que da Vinci faria dessa interpretação. Mas, como se sabe, há um instrumento privilegiado para se ter acesso a essa história individual: o sonho - tema da obra inaugural, segundo muitos, da psicanálise (Die Traumdeutung). Aliás, e esse ponto é importante, a fenomenologia e a psicanálise restituem um modo de pensar que o pensamento objetivo recusa: "os pretensos fenômenos do sonho, do mito e, em geral, da existência, pois eles se encontram impensáveis e não querem dizer nada que eles possam ter por tema" (Merleau-Ponty, 1967, pp. 334-335). 
Entretanto, Merleau-Ponty não compartilha da metapsicologia freudiana. A seu ver, é preciso dizer as descobertas freudianas numa outra linguagem. É o caso, por exemplo, da distinção entre conteúdo latente e conteúdo manifesto. $O$ filósofo se vale principalmente da análise de Politzer na compreensão dessa distinção. Lembremos assim como este afirmava que a primeira descoberta verdadeira da psicanálise é o sentido concreto e individual do sonho. Mas o que isso significa para Politzer? Grosso modo:

1) aquilo que o sujeito narra do seu sonho é verdadeiro - não que seja exatamente isso que ele tenha sonhado/vivido, mas aquilo que ele narra faz sentido para ele (modo de relacionar a verdade do seu sonho à sua história pessoal);

2) essa narração é a manifestação de algo que o sujeito vivencia como seu. Por isso não pode ser compreendida numa terceira pessoa, ou como uma simbologia, em geral, anônima.

Isso, para Politzer, significava afirmar um verdadeiro fato psicológico: o sonho tem um sentido e o ato de interpretar jamais abandona o plano do indivíduo singular. Mas poderíamos perguntar: o que o sujeito narra?

\section{A linguagem do sonho}

Politzer afirma que o objetivo de Freud na interpretação era partir das significações coletivas tradicionais da fala para alcançar as significações individuais. Ou seja, interpretar seria compreender a significação que um sentido tem para o indivíduo e não sua significação usual. Assim, para Politzer, a narrativa convencional seria o que Freud denomina de conteúdo manifesto; já o conteúdo latente, a significação individual. Com isso Politzer pode afirmar que, no fundo, o sonho tem somente um conteúdo: como sua narrativa não pode ser compreendida numa linguagem convencional, trata-se de se ater exclusivamente numa significação: a individual, que só pode ser apreendida pela análise. Politzer nega desse modo que se possa compreender o conteúdo latente como uma espécie de texto primitivo que seria necessário traduzir simbolicamente. Mas afirma, por outro lado, que se é possível pensarmos o simbolismo do sonho com uma natureza diferente do simbolismo de um homem desperto, uma vez que o próprio sujeito que sonha desconhece essa simbologia.

Além do que, Politzer, com termos tal como montagem, caminha para uma explicação estrutural - para a explicação de algo análogo do que dizíamos com termos merleau-pontyanos: a compreensão da elaboração da forma geral de vida. Que se veja essa passagem, por exemplo: 
com efeito, o que quer dizer exatamente quando se afirma que tal lembrança infantil explica tal sonho? Trata-se essencialmente de mostrar que na base do sonho em questão se encontra uma montagem que constitui a significação de uma lembrança infantil. Mas resulta dessa própria constatação que a montagem que é a base da lembrança infantil está presente no sonho, e consequentemente que a aparição da lembrança não suporta a revelação de uma realidade psíquica distinta do sonho mesmo, mas permitir simplesmente, a identificação da montagem atualmente presente no sonho tal como é. (Politzer, 1968, p. 186)

Algo no mesmo tom podemos encontrar nessa passagem de Merleau-Ponty (2002a), mesmo em La Structure du Comportement. Comparemos:

a lembrança infantil que oferece a chave do sonho, o evento traumático que leva a uma ação e que a análise consegue colocar a nu não são causas do sonho ou do comportamento. São para o analista o meio de compreender uma montagem ou uma atitude presente. (p. 193)

De fato, Merleau-Ponty incorpora em grande parte essa leitura de Politzer. Como vemos, o sonho diz da montagem geral do sujeito em relação ao mundo, assim como o sintoma. A importância da interpretação reside nisso: na possibilidade de se poder revelar a atitude geral do sujeito:"há sintomas sexuais na origem de todas as neuroses, mas esses sintomas, se se lê bem, simbolizam completamente uma atitude, seja, por exemplo, uma atitude de conquista, seja uma de fuga" (Merleau-Ponty, 1967, p. 185). Merleau-Ponty também é sensível à interpretação politzeriana do conteúdo manifesto e do conteúdo latente. Entretanto, ele tem sua própria linguagem para destacá-los. Por um lado, o conteúdo manifesto, não pode ser pensado como uma linguagem transparente, tal como uma filosofia da consciência tenderia a fazer. Já afirmar que existe um conteúdo latente não nos leva a instaurar outra consciência, assim como ocorre com uma psicologia do inconsciente.

A revelação do sonho não seria assim uma espécie de tradução de um conteúdo manifesto para uma segunda narrativa ou para uma linguagem figurada. Na verdade, eles se sobredeterminam. Poderíamos falar de dois regimes da linguagem: de um lado, do sujeito desperto, do outro, do sujeito onírico. Ou seja, a linguagem de um sujeito onírico não é a mesma do sujeito desperto. Quer seja, a linguagem do sonho tem sua própria gramática que não é traduzível em nossa linguagem simbólica:

a significação sexual não é inconsciente e menos ainda "consciente", porque o sonho não "significa", como na vida desperta, relacionado uma ordem de fato a uma outra, e se engana igualmente fazendo cristalizar a sexualidade em "re- 
presentações inconsciente" e colocando no fundo do sonhador uma consciência que evoca seu nome. (Merleau-Ponty, 1967, p. 437)

Isso não nega que haja um sentido no sonho, mas essa significação não é uma relação simbólica como o símbolo é pensado para um homem desperto: não uma relação do signo ao significante, mas "encerra verdadeiramente seu sentido, que não é um sentido nocional, mas uma direção de nossa existência" (Merleau-Ponty, 1967, 329). Uma direção que é "a pulsão de minha existência. Sua sístole e sua diástole" (p. 330). Para Merleau-Ponty, trata-se de um valor afetivo, com implicações existenciais (intencionas), onde tudo é simbolizado por tudo em nossa existência e onde o saber objetivo se perderia em fixar uma simbolização unívoca.

Para compreendermos isso, lembremos novamente que Politzer já destacava que a psicanálise ainda trazia alguns resquícios clássicos, principalmente na noção de inconsciente. Para ele, o conteúdo latente do sonho não provaria a existência do inconsciente. Isso porque essa noção seria apenas uma exigência realista, já que todos os problemas da psicanálise poderiam se voltar ao concreto. Nesse sentido, não há nenhum conteúdo consciente ou inconsciente para Politzer, o que existe é uma significação na ação que não está dissociada do drama pessoal. Seria assim no comportamento humano que deveríamos nos debruçar, e não em algo anterior ao próprio comportamento:"o conteúdo latente, quer dizer, o conhecimento do sentido do sonho não pode estar antes da análise nem consciente, nem inconsciente: ele não existe, porque a ciência não resulta da obra do sábio" (Politzer, 1968, p. 205). Isso significa que existe uma significação de ordem existencial (o sentido do comportamento humano), o que é bem diferente de instaurar uma instância inconsciente que supostamente motivasse minha ação.

Dizer, desse modo, que o conteúdo latente é inconsciente, traz para Merleau-Ponty vários equívocos. $O$ sujeito que sonha não tem por tema se o conteúdo é ou não sexual, por exemplo. Primeiro, porque, sendo a sexualidade um modo de se relacionar com o mundo, ela está em toda parte e em parte alguma: não há como o sujeito destacar um fundo sexual de um não sexual no sonho. Ou, como diz Politzer (1968),"mas se vê ao mesmo tempo que a ignorância do sentido do sonho pelo sonhador não prova a existência do inconsciente" (p.161). Depois, porque o caráter sexual é a atmosfera geral do sonho, o conteúdo "é de si ambíguo e não pode se especificar como sexualidade" (Merleau-Ponty, 1967, p.437).Noutros termos, ao afirmar que todo sonho pode ter mais de um sentido, dizse igualmente que a sexualidade pode se apoiar em qualquer coisa, nos deixando num embaraço: se ela se apoia em qualquer ato, se ela está em toda parte e deixa tudo ambíguo até nos atos mais simples, como sei então se tal sonho é ou não sexual? 
Merleau-Ponty (1967) reconhece essa ambiguidade ao dizer que a sexualidade está sempre no ar:"a sexualidade não transcende a vida humana nem figura em seu centro por representações inconscientes. Ela está constantemente presente como uma atmosfera" (p. 196). Há como uma osmose entre a sexualidade e a existência, tornando impossível distinguirmos se tomamos uma decisão por uma motivação sexual ou nãoesta se dilui em nossa existência, pois

\begin{abstract}
a existência é em si indeterminada por causa de sua estrutura fundamental, já que ela é a própria operação através da qual o que não tinha sentido adquire um sentido, o que só tinha um sentido sexual adquire uma significação mais geral, o acaso se faz razão enquanto ela é a retomada de uma situação de fato. Chamaremos de transcendência este movimento pelo qual a existência, por sua conta, retoma e transforma uma situação de fato. (p. 197).
\end{abstract}

Nesse sentido, era preciso ao filósofo dizer que há um princípio de indeterminação, uma vez que o equívoco é essencial à vida humana, pois tudo que vivemos e pensamos tem sempre vários sentidos: "há formas confusas, relações privilegiadas, de forma alguma 'inconscientes', e das quais sabemos muito bem que são equívocas, que têm relação com a sexualidade sem evocá-la expressamente" (Merleau-Ponty, 1967, p. 197). Como atmosfera ambígua, a sexualidade é coextensiva à vida. Assim, retomando o caso da jovem descrita acima, sua recusa em falar não poderia ser lida como uma recusa inconsciente. Certamente tem um sentido: trata-se do modo que ela decide elaborar sua montagem, sua forma geral de vida, diante da interdição de sua libido. Mas como é possível essa escolha?

\title{
Uma decisão nem consciente, nem inconsciente
}

Para Merleau-Ponty, podemos pensar assim: ao decidir pela afonia, a jovem não escolhe um modo de recusa ao acaso, nem conscientemente, nem inconscientemente, nem mesmo porque quer. Na verdade, o filósofo compara essa decisão com a "perda de uma lembrança". Ele se pergunta: por que não somos capazes de lembrar certas situações? Segundo o filósofo, porque elas pertencem a uma "região" de nossa vida que recusamos assumir sua significação.É por isso que ele destaca como o esquecimento é um ato - uma escolha de manter à distância, ao fundo, porque não se é capaz de lidar com tal significação. Assim, não delibero esquecer isso ou aquilo: escolho (diante do meu drama) esquecer e resisto que tal venha à tona.É desse modo que o filósofo compreende a resistência: uma recusa de uma relação intencional que vise uma "região de nossa experiência, uma certa categoria, um certo tipo de lembrança" (Merleau-Ponty, 1967, p. 189). 
Do mesmo modo não se trata de um ato da vontade, porque isso suporia um campo de possibilidades entre as quais se poderia escolher:

eis Pierre, posso falar com ele ou não Ihe endereçar a fala. Se, por outro lado, me torno afônico, Pierre não existe mais para mim como interlocutor desejado ou recusado, é todo o campo de possibilidades que se despedaça, eu me separo mesmo desse modo de comunicação e de significação que é o silêncio. (pp. 189-190)

Isso é fundamental para Merleau-Ponty: em sua primeira obra ele destacava como o organismo é capaz de impor uma norma, segundo uma orientação privilegiada de conduta - afirmando assim um comportamento privilegiado. Aqui, essa recusa busca também uma forma privilegiada de conduta - no caso, de defesa. Com isso o filósofo pode destacar como condutas preferenciais estão no fundo da existência. Mesmo que ela tenha escolhido sair do sintoma na infância (seja por qual motivo for), essa conduta, que (aparentemente) funcionou (porque deve ter sido uma forma menos angustiante de lidar com uma perda) permanece como uma conduta possível e preferencial na sua vida diante de outros impasses.

Essa busca de uma conduta preferencial nos destaca também como a história libidinal é uma elaboração de uma forma geral de vida: "essas motivações faz render uma sensibilidade particular da garganta e da boca em nosso sujeito, que poderia estar ligado à história de sua libido e à fase oral da sexualidade" (Merleau-Ponty, 1967, p. 188). Uma história que firma o modo fundamental de se relacionar com o mundo: tanto em sua dimensão dramática, quer dizer, em sua relação com o passado, quanto em sua relação consigo, com outrem e com o mundo em geral. É essa elaboração a manifestação do sintoma da jovem:"quando se diz que a sexualidade tem uma significação existencial ou que ela exprime a existência, não se deve compreender senão como uma manifestação ou um sintoma de um drama existencial" (p. 194).

Nosso problema se precisa aqui. O caso é importante porque demonstra que essa escolha, essa fixação numa forma de conduta, não significa que o sujeito esteja condenado a viver nessa forma de vida: significa que sua liberdade está apoiada em seu ser em situação - a patologia seria exatamente a redução do que é possível ao sujeito diante de uma situação. Lembremos que a experiência, segundo Merleau-Ponty, é um modo do homem pôr em forma um mundo. Assim, mesmo numa situação patológica há uma experiência: o sujeito segue uma norma, coloca o mundo em certa forma - mas com isso ele pode estar restringindo seu poder de ação.

No caso descrito, por um tratamento psicológico e pela mãe ter voltado atrás com sua interdição (diante da afonia da filha), ela consegue 
voltar a falar. Isso porque "o doente não é jamais absolutamente separado do mundo intersubjetivo, jamais totalmente doente" (Merleau-Ponty, 1967, p. 191). Mas isso só é possível se levarmos a sério que a "cura" da jovem (pelo menos o fato de retomar a fala) mostra uma mudança possível da estrutura do sujeito - não pelo fato deste tomar conhecimento de seu sintoma, mas por uma mudança afetiva com outrem:

em todo caso a tomada de consciência, nos tratamentos psíquicos, permaneceria puramente cognitiva, o doente não assumiria o sentido de seus distúrbios que acabam de ser revelados sem a relação pessoal que travou com o médico, sem a confiança e a amizade que ele lhe traz e a mudança da existência que resulta dessa amizade. (p. 190)

O importante para Merleau-Ponty, longe de ser a eficácia clínica,é a capacidade da consciência se fragmentar:"a jovem filha não cessa de falar,ela 'perde' a voz como se perde uma lembrança" (Merleau-Ponty, 1967, p. 188). Ou seja, ao"perder" a voz, ela barra possibilidades de se relacionar com o mundo, restringindo seu acesso à totalidade de sua vida. Assim, quando o sujeito diz não lembrar de algo, ele está resistindo em colocar à tona uma "região de sua vida" - está agindo como se aquela região fosse isolada da consciência, ficasse barrada do todo. Trata-se de uma escolha que está "abaixo do saber e da ignorância, da afirmação e da negação voluntária" (p.189).

Nesse sentido, para o filósofo,é possível uma interpretação em sentido amplo da psicanálise, uma vez que a consciência não é definida como posição explícita de seu objeto, mas uma significação não percebida, como já havia se referido em La Structure du Comportement. Merleau-Ponty percebe assim de um modo muito original aquilo que Lacan desenvolve em seus primeiros trabalhos ${ }^{1}$ ao aproximar a noção de inconsciente dos

1 Richard Boothby nota muito claramente esta aproximação com a Gestalttheorie em Lacan. Por exemplo, ele nos diz que a análise da resistência em Le Seminaire I nos apontava exatamente a isto: no momento em que o paciente está por falar, está por deixar emergir um pensamento primordial, ele acaba por desviá1o. Mas como que é possível esta "substituição" de um pensamento por um outro (que não seja diretamente a lembrança de algo penoso ao paciente)? Como é possível explicar este processo de defesa? Boothby, nesse ponto, nos lembra dos problemas gestaltistas: em todo campo perceptivo, sempre percebemos uma figura sob um fundo, o que, para Boothby, é tentador comparar com a ação da repressão aos processos pelos quais os conteúdos do "fundo" da consciência são relegados à "margem" (Boothby, 2001, p.73). Noutras palavras, Boothby apoia-se na ideia de defesa primária de Freud, nessa função do aparelho psíquico de desviar o destino de passagem de energia, substituindo uma imagem por outra, a um objeto menos hostil ao paciente, onde o fundamental permanece sob um fundo e a substituição aparece como figura. Em verdade, o que é substituído só emergiria sob a condição de um fundo, onde as imagens seriam associadas segundo esta função de defesa: "a figura do campo fenomenal se perde somente por virtude de ser substituída por detalhes do fundo ao seu redor" (p.76). Haveria como que uma contiguidade 
problemas gestaltistas. Eis uma passagem de uma lição sua (Les sens et l'inconscient) ministrada dois anos após a Phénoménologie de la Perception que confirma sua posição:

todo conhecimento, diz a psicologia da forma, é a percepção de uma figura sobre um fundo. Ela deve se rodear de um halo de não conhecido ou menos conhecido por uma margem de não atenção, que não é um suplemento, mas um elemento essencial... É preciso rodear o conhecimento de uma mancha de consciência que não põe o objeto enquanto objeto. É o vivido não denominado, o que Freud denomina incorretamente de inconsciente. (Merleau-Ponty, 2002b, p. 127)

Entendemos assim afirmações, à primeira vista, incompreensíveis, como essa:"a psicanálise, ela mesma salva de seus primeiros dogmas, é o prolongamento normal de uma psicologia da forma consequente" (Merleau-Ponty, 2004, p. 105). Na verdade, esse modo de pensar o inconsciente será marcante nas suas obras da década de 50, principalmente associando-o à noção de impercepção: aquilo que conto em toda percepção.

Tudo se passa como se Merleau-Ponty buscasse alargar o domínio da reflexão, buscando apreender aquilo que a filosofia até então deixava de fora. Ou seja, o filósofo pretende mostrar a dependência da reflexão de uma vida irrefletida, impercebida.Trata-se assim de buscar apreender o ambíguo, o vivido, exatamente o que constitui o irrefletido, segundo o filósofo, sem com isso recorrer a algo exterior à consciência. Refletir é assim buscar o originário. Compreendemos assim porque, para o filósofo, ao dizer que ajo de tal modo que o "eu penso" não se reconhece, seguindo uma lógica vivida, não significa dizer que exista algo como uma instância inconsciente:

a consciência não é nem posição de si, nem ignorância de si, ela é não dissimulada a ela mesma, quer dizer que ela não é nada nela que não se anuncia de algum modo, apesar de não precisar conhecer expressamente...; o vivido é vivido por mim, eu não ignoro os sentimentos que recalco e, neste sentido, não existe inconsciente. (Merleau-Ponty, 1967, pp. 342-343)

de imagens, que se substituiriam por um movimento lateral, exatamente aquilo que Lacan iria entender como"metonímia" (p.77). Ou, na terminologia freudiana, a catexia seria equivalente à função dos processos do campo perceptivo: haveria um investimento de energia que foca a atenção e o interesse, deixando sempre algo à margem, assim como a repressão funcionaria como num automatismo de toda estrutura ativa perceptiva. 


\section{A case of Binswanger in the light of Merleau-Ponty}

Abstract: In this article, we intend to deal with a case of Binswanger privileged by Merleau-Ponty. In this case, the philosopher develops the question of the statute of the symptom as a way of elaboration of life, but arrives in an impasse: how to think this elaboration without denying that the subject complete restructures itself in front an impasse? Furthermore, what means to say that the subject elaborates a new way of life? We will see how this Merleau-Ponty's reflection of psychoanalyses is peculiar, leading him to deny a key concept of Freudian's metapsychology: the unconscious.

Keywords: Symptom. Decision. Unconscious. Drama. Meaning.

\section{Un cas de Binswanger sur le biais de Merleau-Ponty}

Résumé: Je prétends, dans cet article, aborder un cas de Binswanger privilégié par Merleau-Ponty. Dans ce cas, le philosophe développe la question du statut du symptôme comme une forme d'élaboration de vie, mais arrive dans une impasse: comment penser cette élaboration sans nier que le sujet se restructure totalement en face d'une impasse? Bien plus, qu'est-ce que signifie dire que le sujet élabore une nouvelle façon de vie? Nous verrons comme l'analyse merleau-pontienne de la psychanalyse est singulier, conduisant lui à nier un concept clé de la metapsychologie freudienne:l'inconscience.

Mots-clés: Symptôme. Décision. Inconscience. Drame. Sens.

\section{Un caso de Binswanger bajo la óptica de Merleau-Ponty}

Resumen: Me propongo en este artículo ponerme frente a un caso de Binswanger privilegiado por Merleau-Ponty. El filósofo desarrolla el tema de los síntomas como una forma de elaboración de la vida, pero llega en un dilema: ¿cómo pensar sin que esta elaboración nos lleve a negar que el tema es completamente reestructurado en un callejón sin salida? Aparte de eso, ¿qué significa que el sujeto desarrolla una nueva forma de vida? Vamos a ver cómo un análisis merleau-pontyana del psicoanálisis es peculiar, haciéndolo negar un concepto clave dela metapsicología freudiana: el inconsciente.

Palabras-clave: Síntoma. Decisión. Inconsciente. Drama. Sentido. 


\section{Referências}

Boothby, R. (2011). Freud as philosopher. New York: Routledge.

Merleau-Ponty, M. (1988). Merleau-Ponty à la Sorbonne. Dijon: Cynara.

Merleau-Ponty, M. (1959-1960). La nature et logos:le corps humain (Vol. 17). (Trabalho inédito)

Merleau-Ponty, M. (1957). La nature ou le monde du silence (Vol 6 - BN: 9587). (Trabalho inédito)

Merleau-Ponty, M. (1967). Phénoménologie de la perception. Paris: Gallimard.

Merleau-Ponty, M. (2004). Sens et non-sens. Paris: Gallimard.

Merleau-Ponty, M. (2002a). La structure du comportement. Paris: Quadrige.

Merleau-Ponty, M. (2002b). L'union de l'âme et du corps chez malebranche, Biran et Bergson. Paris: Vrin.

Piaget, J. (1980). Seis estudos de psicologia (M. Magalhães D’ Amorim \& P.S. Lima Silva, trad.). Rio de Janeiro: Forense Universitária.

Piaget, J., \& Inhleder, B. (1986). A psicologia da criança. (O. M. Cajado, trad.). São Paulo: Difel.

Politzer, G. (1968). Critique des fondements de la psychologie. Paris: PUF.

Savoureux, H. (1939, févreier). De la psychanalyse. La Nouvelle Revue Française, 27(305). 
Ronaldo Manzi Filho, doutorando em Filosofia na Universidade de São Paulo, aluno do curso de formação em Psicanálise no Centro de Estudos Psicanalíticos. Bolsista CNPq. Endereço para correspondência: Rua Heitor Penteado, 1797, ap. 13, Sumarezinho, São Paulo, SP, Brasil. CEP: 05437-002. Endereço eletrônico: manzifilho@hotmail.com

Recebido em: 24/08/2010

Aceito em: 08/05/2011 